\title{
Model tests for surge height of rock avalanche-debris flows based on momentum balance
}

\author{
Haixin Zhao $^{1,4} \cdot$ Lingkan Yao ${ }^{1,2,3}$
}

Received: 30 January 2019/Revised: 4 September 2019/Accepted: 25 September 2019/Published online: 25 October 2019

(C) The Author(s) 2019

\begin{abstract}
Rock avalanche-debris flows triggered by earthquakes commonly take place in mountainous areas. When entering a body of water, due to good fluidity they can move for some time instead of halting in water. In this study, we proposed a method for calculating the surge height of rock avalanche-debris flows based on momentum balance and designed a series of model tests to validate this method. The experimental variables include the initial water depth, landslide velocity, and landslide volume. According to the experimental results, we analyzed the maximum wave height in sliding zone based on momentum balance. In addition, we investigated the surge height and proposed the calculation method in propagating zone and running up zone. In this way, we can find out the surge height in different areas when a rock avalanche-debris flow impacts into the water, which could provide a basis for analyzing the burst of barrier lakes.
\end{abstract}

Keywords Surge - Rock avalanche-debris flow · Momentum balance $\cdot$ Barrier lake

Lingkan Yao

yaolk@swjtu.edu.cn

1 School of Civil Engineering, Southwest Jiaotong University, Chengdu 610031, China

2 MOE Key Laboratory of High-Speed Railway Engineering, Southwest Jiaotong University, Chengdu 610031, China

3 National Engineering Laboratory for Technology of Geological Disaster Prevention in Land Transportation, Chengdu 610031, China

4 Institute of Mountain Hazards and Environment, Chinese Academy of Sciences, Chengdu 610041, China

\section{Introduction}

Landslide surges are a major cause of barrier lake collapse, which can threaten highways, railways, and key facilities in mountainous regions [1-3]. One typical example is the ice lake collapse on July 15, 1988, in Midui, China. It was reported that a glacier with a total volume of $3.6 \times 10^{5} \mathrm{~m}^{3}$ collapsed into the Midui Ice Lake. The glacier caused a 1.4-m surge, eventually leading to the collapse of the glacial lake. Subsequent burst floods destroyed a nearly $30-\mathrm{km}$ section of the Sichuan-Tibet Highway, which took 6 months to repair [4].

The study of landslide surge has always been of great interest [5-9]. Noda [3] suggested a linear relationship between the height of a landslide surge and the Froude number of the landslide based on a piston model experiment. Huber and Hager [10] carried out model experiments on granular landslides, which took into consideration the impact angle, density, and geometric size of a landslide. By assuming that landslide velocity and thickness were the dominant factors, Fritz et al. [6] evaluated the maximum landslide surge height within the generated surge field. On the basis of the work of Fritz et al. [6], Zweifel et al. [9] investigated the effect of landslide density on surge height using different densities-including ice landslides-in their experiments. Ataie-Ashtiani and Najafi-Jilani [5] studied the effects of the underwater movement of solid landslides, granular landslides, and finite deformation granular landslides on wave height by setting the initial position immediately beneath the still water surface. Zitti et al. [11] assumed that the avalanche was a suspended particle after it entered a body of water and established a theoretical model to describe the momentum transfer between the particle and fluid when an avalanche enters a two-dimensional water body. The independent and 
dependent variables in the model were then reconstructed into a dimensionless form for scale analysis, and the theoretical approximate solution of the near-field wave amplitude of the surge was obtained. Mulligan and Take [12] studied the impact of a landslide on a water body. They determined that the momentum flux is the main driving force of a surge induced by a two-dimensional granular landslide and established the idealized formula of the maximum amplitude of the surge in the near field. Following the analysis of Mulligan and Take [12], Han and Wang [13] established a three-dimensional physical model of reservoir landslide surges and deduced the theoretical expression of the maximum near-field amplitude of a surge under the background effects of a three-dimensional bulk landslide.

Numerous landslide surge model experiments have been conducted with solid blocks, but clastic material is seldom used. In addition, the movement after the landslide enters the water is ignored. Due to water pressure and the friction at the bottom of the block, a solid block cannot move long distance after entering a body of water. However, as to a rock avalanche-debris flow, this is not the case. The distance a rock avalanche-debris flow travels within a body of water is much longer than that of a block.

In this study, we propose a method for calculating the landslide surge height based on momentum balance. Firstly, we analyze the surge height based on momentum balance and proposed a theoretical formula to calculate the surge height near the impact pit. Then, we conducted a series of model tests in order to verify the results of the theoretical analysis. Meanwhile, we investigated the surge height and proposed the calculation method in propagating zone and running up zone. Finally, we analyzed the experimental results and discussed the further research.

\section{Theoretical analysis of surge height based on momentum balance}

Suppose that a landslide made up of granular material rolls from a high position into a body of water, and the granular mass acts as a rolling ball. We ignore the effect of the friction inside the granular material. We also ignore the effect of the friction between the granular material and the chute. According to the conservation of energy, we obtain

$\frac{1}{2} m_{\mathrm{s}} v_{\mathrm{s}}^{2}=m_{\mathrm{s}} g H$,

where $m_{\mathrm{s}}$ is the mass of the granular material, $v_{\mathrm{s}}$ is the velocity of the granular material, $g$ is the gravitational acceleration, and $H$ is the vertical distance from the initial position of the granular material to the horizontal surface. In addition, there is $v_{\mathrm{s}}=\sqrt{2 \mathrm{~g} H}$.

The change in the momentum of the landslide in the horizontal direction over time $t$ can be expressed as follows:

$\frac{\partial m_{\mathrm{s}} v_{\mathrm{s}} \cos \alpha}{\partial t}=\frac{\rho_{\mathrm{s}} V_{\mathrm{s}} v_{\mathrm{s}} \cos \alpha}{\Delta t_{\mathrm{e}}}$,

where $\alpha$ is the inclusion angle of the slope with the horizontal plane, $\rho_{\mathrm{s}}$ is the bulk landslide density at impact, $V_{\mathrm{s}}$ is the landslide volume, and $\Delta t_{\mathrm{e}}$ is the effective time from landslide impact to wave detachment. Considering the width of the landslide inflow $b$ and the thickness of the landslide $s$, the momentum transfer rate along the horizontal direction within the landslide during the effective time is

$J_{\mathrm{s}}=\rho_{\mathrm{s}} s b v_{\mathrm{s}}^{2} \cos \alpha$.

In this work, we employed a simplified one-dimensional method to analyze the fluid state of a landslide impacting a body of water under hydrostatic conditions, which is shown in Fig. 1. In this case, the momentum of the landslide that is transferred to the body of water is described as a pressure gradient along the $x$-axis, which is generated by the instantaneous static vertical water pressure over a period of time $\Delta t_{\mathrm{e}}$. The initial hydrodynamic pressure on the surface of the water is assessed based on the difference $\eta(x, t)$ in the surface elevation of the water. There is a maximum forward wave amplitude $a_{\max }$ between the impact site and the non-impact site $L$. We define the pressure gradient as

$\frac{\partial P}{\partial x}=\frac{1}{L}\left(\frac{1}{2} \rho g\left(h_{0}+a_{\mathrm{m}}\right)^{2}-\frac{1}{2} \rho g h_{0}^{2}\right)$

where $\rho$ is the density of the water, $\mathrm{a}_{\mathrm{m}}$ is the wave amplitude, and $h_{0}$ is the initial water depth. Equation (5) can be simplified into Eq. (6) to deduce the hydrostatic momentum flux:

$J_{f}=\frac{\rho g\left(h_{0} a_{\mathrm{m}}+\frac{1}{2} a_{\mathrm{m}}^{2}\right)}{L}$.

The idealized hydrostatic momentum flux between the dry granular landslide $\left(J_{\mathrm{s}}\right)$ and the water $\left(J_{\mathrm{f}}\right)$ is

$\frac{\partial m_{\mathrm{s}} v_{\mathrm{s}} \cos \alpha}{\partial t} \frac{1}{b l}=\frac{\partial P}{\partial x}$,

where the landslide's mass can be expressed as $m_{\mathrm{s}}=\rho_{\mathrm{s}} V_{\mathrm{s}}$, the landslide's volume is $V_{s}=s b l, s$ is the product of the landslide's thickness, $b$ is the landslide's width, and $l$ is the landslide's length. Thus, Eqs. (3) and (7) can be used to deduce Eq. (8):

$\frac{\rho_{\mathrm{s}} s v_{\mathrm{s}} \cos \alpha L}{\rho g \Delta t_{\mathrm{e}}}=h_{0} a_{\mathrm{m}}+\frac{1}{2} a_{\mathrm{m}}^{2}$.

One of the positive roots of Eq. (8) is the maximum near-field wave amplitude $a_{\max }$, 


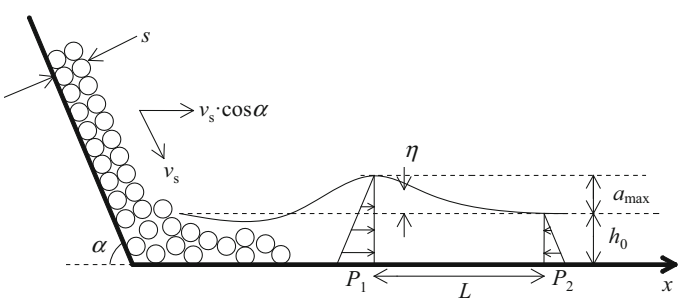

Fig. 1 Schematic of the interaction between the fluid structure of the granular material and the water. $s$ landslide thickness; $\alpha$ inclusion angle of the slope with the horizontal plane; $v_{\mathrm{s}}$ velocity of granular material; $\eta$ surge amplitude of the surge; $a_{\max }$ maximum amplitude of the surge; $h_{0}$ initial water depth; $P_{1}$ the position where the maximum amplitude is generated; $P_{2}$ the position unaffected by surge; $L$ the distance between $P_{1}$ and $P_{2} ; x$ the coordinate of surge

$a_{\max }=\sqrt{h_{0}^{2}+\frac{2 \rho_{\mathrm{s}} s v_{\mathrm{s}} \cos \alpha L}{\rho g \Delta t_{\mathrm{e}}}}-h_{0}$,

where $v_{s}$ can be obtained from Eq. (2) and $L$ is approximately equal to the horizontal distance the granular material travels underwater during the effective time $\Delta t_{\mathrm{e}}$ [12], which can be used to solve for Eq. (10):

$L=\frac{1}{2} v_{\mathrm{s}} \cos \alpha \Delta t_{\mathrm{e}}$.

By combining Eqs. (2), (9), and (10), we derive the formula for calculating the maximum amplitude:

$a_{\max }=\sqrt{h_{0}^{2}+2 \lambda s H \cos ^{2} \alpha}-h_{0}$,

where $\lambda=\rho_{\mathrm{s}} / \rho$ is the ratio of solid to liquid density.

\section{Physical model tests of rock avalanche-debris flows}

\subsection{Experimental setup}

The experiments of rock avalanche-debris flow surge were carried out in the Key Laboratory of High Speed Railway Engineering, Southwest Jiaotong University. Figure 2 shows the experimental setup.

The experimental equipment consists of six parts: the platform, power system, control system, data acquisition system, water tank, and inclined plate. The $4 \mathrm{~m} \times 2 \mathrm{~m}$ platform has a maximum load-bearing capacity of $25 \times 10^{3} \mathrm{~kg}$. The dynamic system can shake both the platform and water tank. The frequency range of the shaking was $0.4-15 \mathrm{~Hz}$, and the displacement range was $-100-100 \mathrm{~mm}$, the acceleration range was $0-1.2 \mathrm{~g}$, and the three-dimensional size of the water tank used to simulate the barrier lake was $3.76 \mathrm{~m} \times 1.76 \mathrm{~m} \times 1.51 \mathrm{~m}$ $(L \times H \times W)$. The boundary of the water tank is a rigid
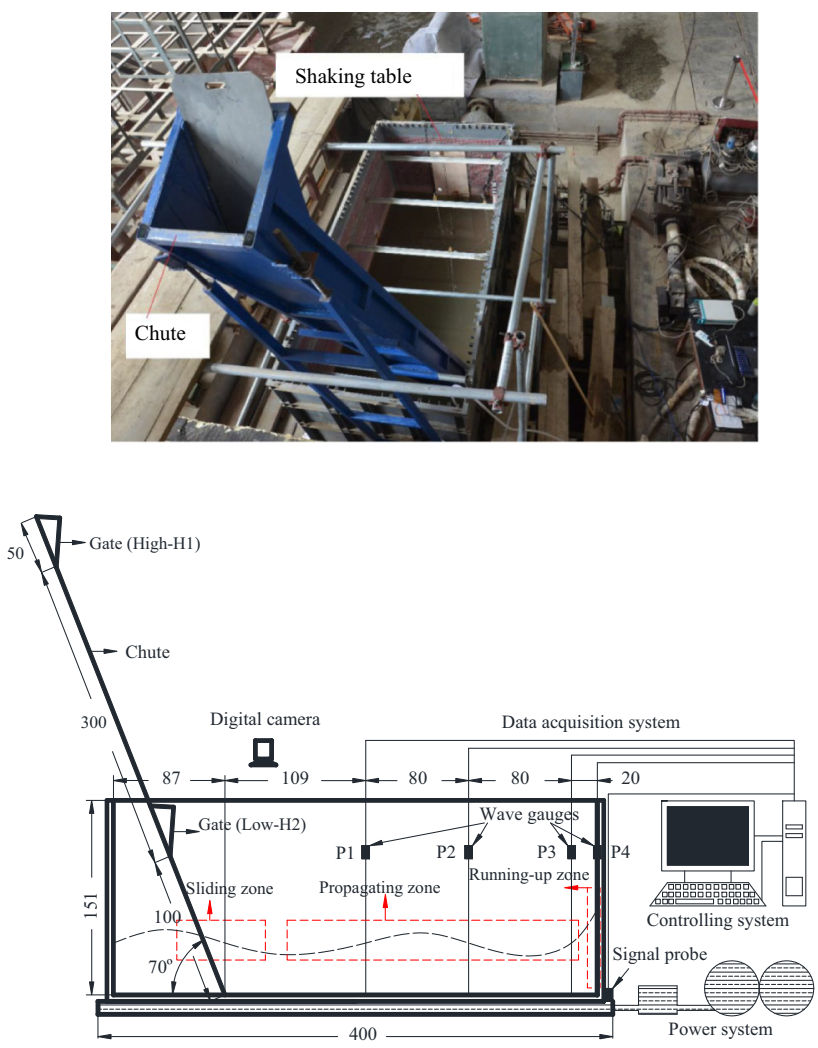

Fig. 2 Schematic diagram of experimental setup

reflective boundary. The dimensions of the water tank and sliders were set according to the size of the Midui Ice Lake [4]. The prototype of the lake and the characteristics of the model lake are shown in Table 1.

When designing the physical model, we adopted Froude similarity and geometric similarity experiment, with a geometric similarity ratio of $1 / 300$. We installed four identical wave gauges $(\mathrm{P} 1-\mathrm{P} 4)$ in the water tank to record the wave height with a length of $1 \mathrm{~m}$ and an accuracy of $\pm 0.5 \mathrm{~mm}$. A recording frequency of $100 \mathrm{~Hz}$ was used. The positions of the gauges are shown in Fig. 2. We used a digital camera to synchronize the movement of the surface waves and the movement of the rock avalanche-debris flow and installed an inclined chute with a length of $4.5 \mathrm{~m}$ and an inclination of $70^{\circ}$ to simulate a landslide gully. An upper gate $(\mathrm{H} 1)$ and a lower gate $(\mathrm{H} 2)$ were installed on the chute. We collected data from four identical wave gauges and used this information to analyze the generation, transmission, and run-up of the landslide surge.

\subsection{Experimental scheme}

Table 2 shows the experimental scheme of the landslide surge. We conducted 18 groups of landslide surge experiments and studied the sizes of the landslide surges resulting 
Table 1 Parameter comparison between prototype lake and model

\begin{tabular}{|c|c|c|c|c|c|}
\hline Parameter & Physical quantity & Model & Prototype & Scaling ratio & Reference ratio \\
\hline \multirow[t]{3}{*}{ Model water tank } & Length $L(\mathrm{~m})$ & 3.76 & 950 & $1 / 252$ & $1 / 300$ \\
\hline & Width $W(\mathrm{~m})$ & 1.76 & 550 & $1 / 313$ & $1 / 300$ \\
\hline & Water density $\rho_{\mathrm{w}}\left(\mathrm{g} / \mathrm{cm}^{3}\right)$ & 1 & 1 & 1 & 1 \\
\hline \multirow[t]{2}{*}{ Rock avalanche-debris flow } & Volume $V_{\mathrm{s}}\left(\mathrm{m}^{3}\right)$ & $0.006-0.020$ & 360,000 & $1 / 376^{3}-1 / 261^{3}$ & $1 / 300^{3}$ \\
\hline & Froude number in the water $F_{\mathrm{s}}$ & $0.96-3.31$ & 1.52 & $0.6-2.2$ & 1 \\
\hline
\end{tabular}

Table 2 Experimental conditions for granular material surge tests

\begin{tabular}{llll}
\hline Tests tag no. & \multicolumn{4}{l}{ Experimental conditions } \\
\cline { 2 - 4 } & $M_{\mathrm{s}}(\mathrm{kg})$ & $v_{\mathrm{s}}(\mathrm{m} / \mathrm{s})$ & $h_{0}(\mathrm{~m})$ \\
\hline Cases $1-18$ & $10,20,30$ & $1.64,3.28$ & $0.1,0.2,0.3$ \\
\hline
\end{tabular}

Note Cases 1-18 are combined by three clastic landslide qualities $M_{s}$, two landslide velocities $v_{s}$, and three initial water depths $h_{0}$; for example, Case 1 means $M_{s}=10 \mathrm{~kg}, v_{\mathrm{s}}=1.64 \mathrm{~m} / \mathrm{s}, h_{0}=0.1 \mathrm{~m}$, and Case 2 means $M_{s}=20 \mathrm{~kg}, v_{\mathrm{s}}=1.64 \mathrm{~m} / \mathrm{s}, h_{0}=0.1 \mathrm{~m}$

from different clastic landslide qualities, landslide velocities, and initial water depths.

We simulated a rock avalanche-debris flow using homogeneous sand with a particle size of $4 \mathrm{~mm}$ and a bulk density of $1.48 \times 10^{3} \mathrm{~kg} / \mathrm{m}^{3}$. The parameters of the rock avalanche-debris flow are listed in Table 3 .

In this table, $s_{1}$ is the thickness of the landslide at the upper position (H1) and $s_{2}$ is the thickness of the landslide at the lower position $(\mathrm{H} 2)$.

Figure 3 shows the movement of the rock avalanchedebris flow before and after entering the water.

\section{Establishment of a formula for calculating rock avalanche-debris flow surge}

\subsection{Analysis of the landslide surge distribution}

In tests, the rock avalanche-debris flow surge was simulated by granular material flowing into water. The surge was then transmitted outward and rebounded when it encountered an obstacle. During this process, we collected data with four sensors (P1-P4). Due to the complex form of the surge when a rock avalanche-debris impacts into the water [5, 14], including impact and penetration, flow separation, cavity formation, cavity collapse slide run-out along channel bottom, and slide detrainment, particularly for rock avalanche-debris flow surges, the landslide is still moving underwater during the development of the wave. Thus, P1 could only approximately record the surge characteristics near the point where the slide entered the water. During the transmission process, $\mathrm{P} 2$ collected the surge
Table 3 Parameters of rock avalanche-debris flow

\begin{tabular}{lllllll}
\hline No. & $M_{\mathrm{s}}(\mathrm{kg})$ & $\rho_{\mathrm{s}}\left(\times 10^{3} \mathrm{~kg} / \mathrm{m}^{3}\right)$ & $V_{\mathrm{s}}\left(\mathrm{m}^{3}\right)$ & $b(\mathrm{~m})$ & $s_{1}(\mathrm{~m})$ & $s_{2}(\mathrm{~m})$ \\
\hline 1 & 10 & 1.48 & 0.0067 & 0.4 & 0.015 & 0.023 \\
2 & 20 & 1.48 & 0.0135 & 0.4 & 0.025 & 0.040 \\
3 & 30 & 1.48 & 0.0201 & 0.4 & 0.025 & 0.070 \\
\hline
\end{tabular}
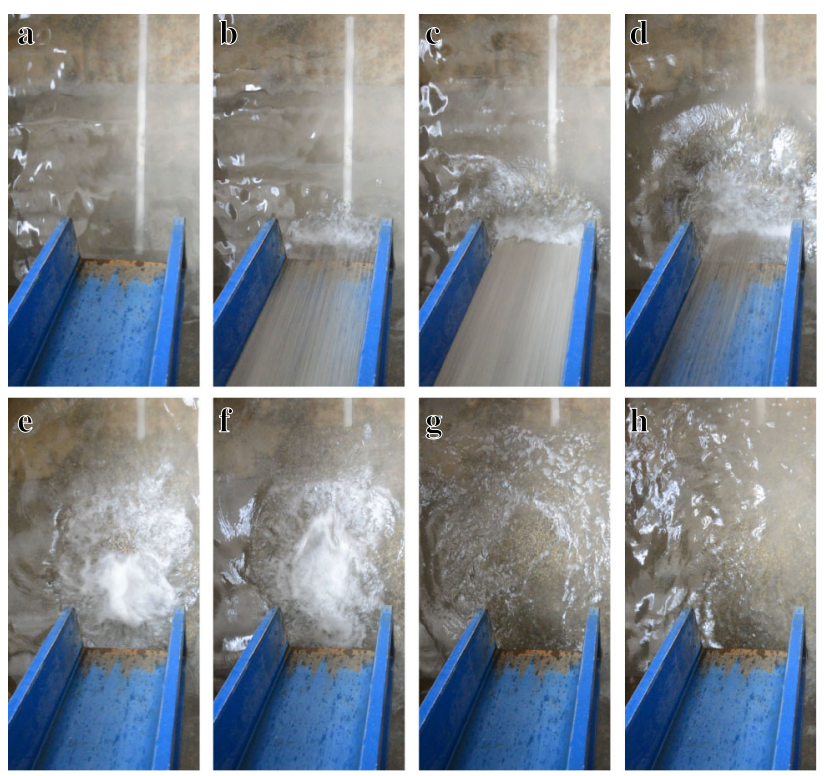

Fig. 3 Rock avalanche-debris flow sliding into the water. a the water surface is undisturbed prior to landslide entry; $\mathbf{b}$ the rock avalanchedebris flow begins to enter the water; c the primary body of the landslide enters the water and forms an obvious shock wave; $\mathbf{d}$ the landslide extrudes within the water and begins to move underwater; e almost the entire rock avalanche-debris flow has entered the water, and the shock wave continues to spread outward; $\mathbf{f}$ the underwater landslide reaches its maximum distance and stops; $\mathbf{g}$ when the shock wave thrusts away part of the water body, there is an obvious impact pit close to where the landslide entered the water; and $\mathbf{h}$ the nearby water backfills, and the sloshing caused by the landslide has been stabilized

transmission data. The 18 groups of collected data revealed that the wave height significantly decreased during transmission of the surge. Due to the rigid reflection of the side wall, when the surge reached the side wall, it rose up along the wall even with a greater wave height than that near the 
entry point. P3 and P4 recorded the final surge height, demonstrating that the wave height near the side wall was the largest. Figure 4 shows the three stages of a surge caused by a fast landslide, which vary with the distance from the entry point. Figure 4 shows that the wave height near the entry point was large and the amplitude of the surge decreased rapidly during transmission by $42 \%-66 \%$ near the entry point. The surge height in its final stage was the largest which was 1.03-1.7 times higher than the value at the entry point. It is found that the size of the surge increases with the initial water depth. Thus, the greater the initial water depth, the smaller the energy consumption of the surge during transmission.

In Fig. 5, linear equations were fitted with the measured surge heights at P1, P2, and P4 and the theoretical ones from Eq. (11).

Due to the complex nature of the surge near the impact point, it was difficult to measure the maximum surge height near the impact pit; however, a stable surge amplitude could be measured in the propagation zone. In Fig. 5, note that the values measured at P1 exhibited a good linear correlation with theoretical values. The values measured at P2 and P4, however, were poorly correlated with the theoretical values. This can be attributed to the effects of the reflective boundary on the transmission process.

\subsection{Calculation of surge height in propagation zone due to clastic landslide}

Previously, we mentioned that the conservation of momentum can be used to calculate the maximum surge height near the impact pit. In the propagating zone, we use an exponential power function similar to Wang et al.'s [15]

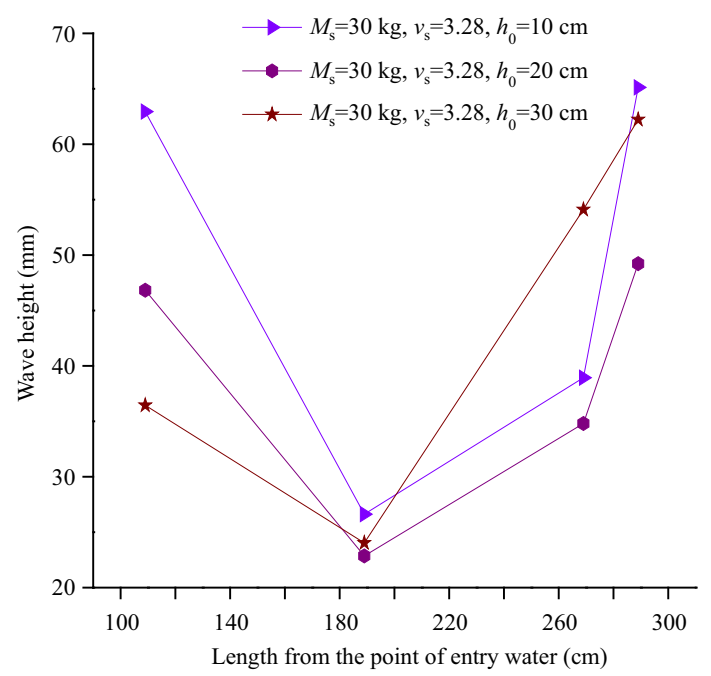

Fig. 4 Change in surge height with distance from the entry point

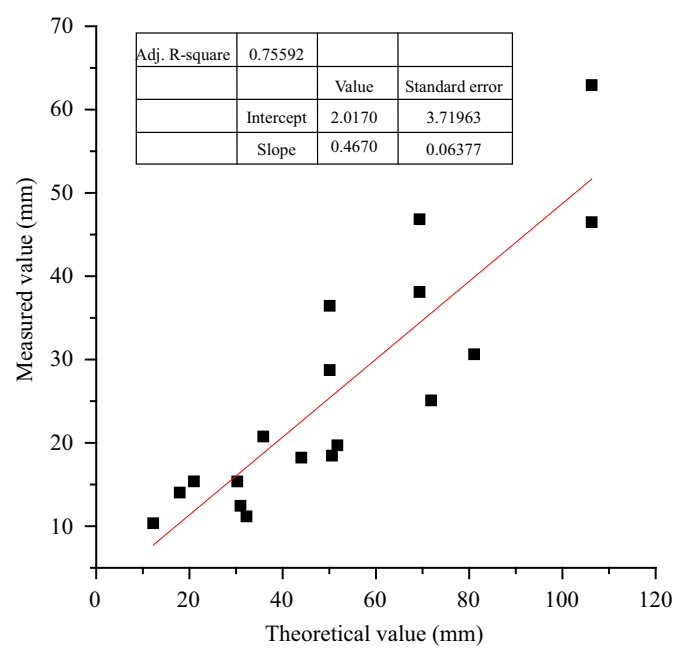

a P1

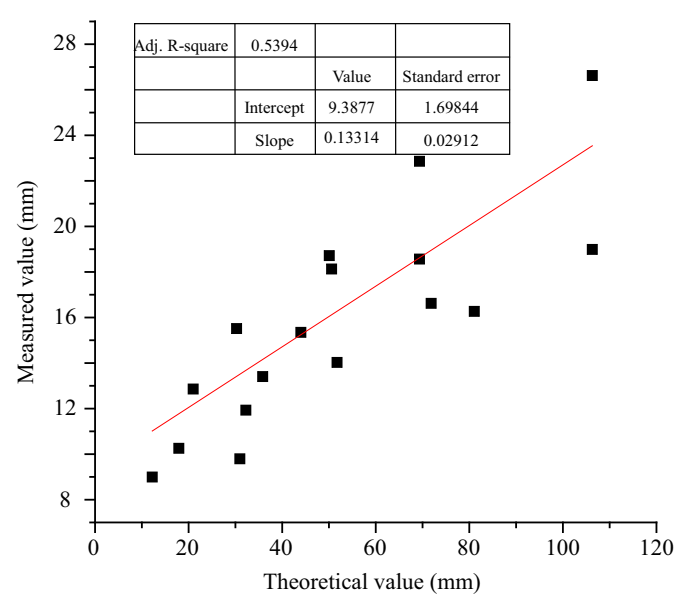

b P2

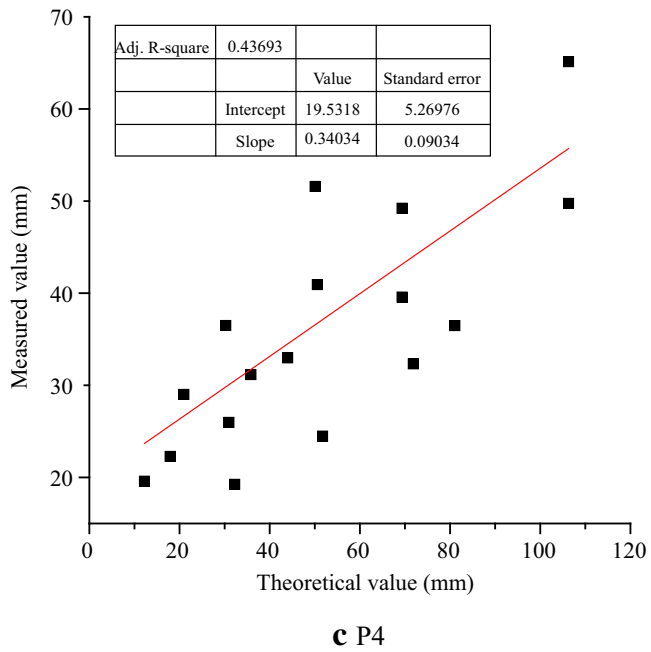

Fig. 5 Linear correlation analysis for theoretical surge height and the measured ones at P1, P2, and P4, which represent, respectively, the characteristics of surge height in sliding zone, propagating zone, and running up zone 
and propose Eq. (12) as a new method for calculating the surge height:

$\frac{a(x)}{a_{\max }}=\xi x^{\tau}$,

where $x$ is the ratio of the distance from the entry point to the length of the flume, and $\zeta$ and $\tau$ are parameters affected by the initial water depth and the mass of the debris flow, respectively. We fit the two parameters using experimental data and input them into Eqs. (13) and (14):

$\xi=f\left(F_{\mathrm{s}}, V, s_{0}\right)$,

$\tau=f\left(F_{\mathrm{s}}, V, s_{0}\right)$.

where

slide Froude number $F_{\mathrm{s}}=\frac{v_{\mathrm{s}}}{\sqrt{\mathrm{g} h_{0}}}$,

dimensionless slide volume $V=\frac{V_{\mathrm{s}}}{b h_{0}^{2}}$,

and dimensionless relative thickness $s_{0}=\frac{s}{h_{0}}$.

Thus, the attenuation law obtained by fitting the experimental data is expressed as Eqs. (18) and (19):

$\xi=1.08 \cdot F_{\mathrm{s}}^{-0.08} \cdot s_{0}^{-0.1754} \cdot V^{0.2053}$,

$\tau=-1.228 \cdot F_{\mathrm{s}}^{0.8058} \cdot s_{0}^{0.3262} \cdot V^{-0.0653}$.

\subsection{Calculation of maximum surge run-up height}

For a rock avalanche-debris flow surge, we found that the wave height at the side wall was the largest, and the run-up was the most significant due to the influence of the side wall effect. Figure 6 illustrates that the maximum water height and the initial water depth of the landslide surge,

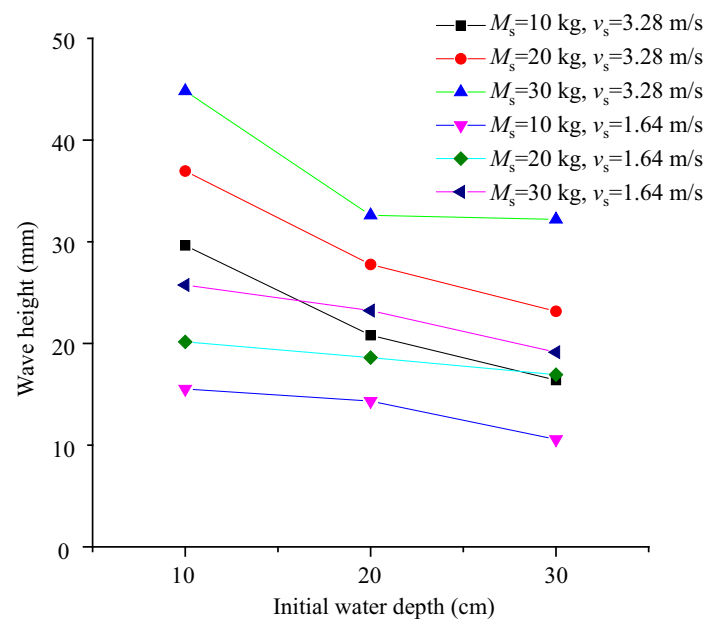

Fig. 6 Relationship between maximum wave height of landslideinduced surges and initial water depth which corresponds to the relationship between the landslide velocity and the landslide volume.

As shown in Fig. 6, as the initial water depth increased, the maximum landslide surge wave height decreased. Additionally, Fig. 6 shows that the maximum height of the landslide surge increased with the landslide velocity and volume. These findings are consistent with the previous studies [6, 14].

In order to further reflect the underwater movement characteristics of rock avalanche-debris flows, we take the duration of the underwater movement of the landslide as a variable.

The dimensionless relative duration of underwater movement can be calculated as

$t_{0}=t \cdot \sqrt{\mathrm{g} / h_{0}}$.

Based on dimensionless analysis, the relationship between the maximum wave height and four dimensionless parameters is defined as

$\frac{h_{\max }}{h_{0}}=f\left(F_{\mathrm{s}}, V, s_{0}, t_{0}\right)$.

Based on a series of experiments, Eq. (21) is rewritten as

$\frac{h_{\max }}{h_{0}}=0.4249 \cdot F_{\mathrm{s}}^{0.5345} \cdot s_{0}^{-0.2482} \cdot t_{0}^{-0.2119} \cdot V^{0.8461}$.

We fit the calculated data with the experimental data. The results are shown in Fig. 7. The correlation coefficient between the measured and calculated values by Eq. (22) is 0.96. Therefore, Eq. (22) could be used to estimate the maximum surge height in running up zone.

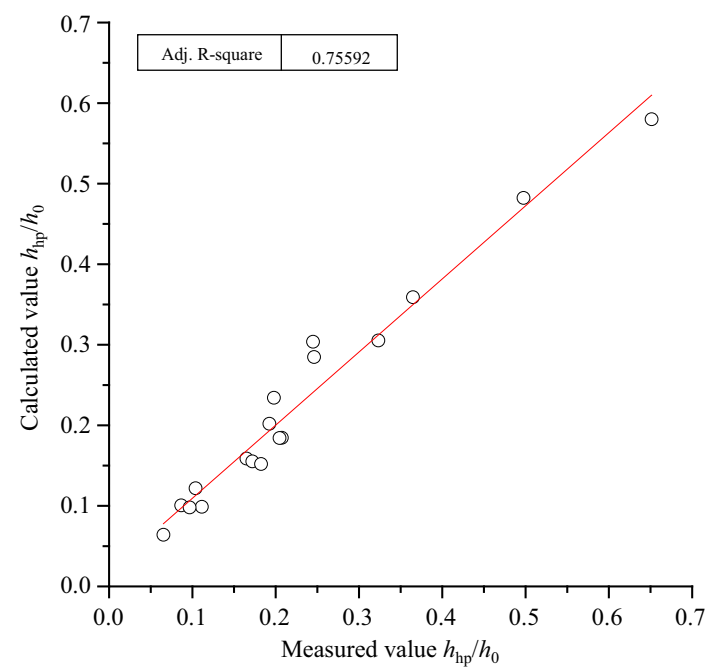

Fig. 7 Comparison of the measured and calculated values using Eq. (22) 


\section{Conclusions}

In this work, we proposed a theoretical formula to calculate the surge height generated by a rock avalanche-debris flow near the impact pit. We carried out a series of model tests to verify the rationality of theoretical derivation. The test results show that variations in the measured value near the impact point and in the calculated result are consistent with the change of experimental variables. Due to the complexity of the wave making process, the method of calculating the surge height near the impact pit is a theoretical model, by which we can only approximately verify the rationality of theoretical derivation. In future studies, we will further refine the model and verify its rationality.

Acknowledgements This research was supported by the National Program on Key Research Projects of China (Grant No. 2016YFC0802206) and the National Natural Science Foundation of China (Grant No. 41571004).

Open Access This article is distributed under the terms of the Creative Commons Attribution 4.0 International License (http:// creativecommons.org/licenses/by/4.0/), which permits unrestricted use, distribution, and reproduction in any medium, provided you give appropriate credit to the original author(s) and the source, provide a link to the Creative Commons license, and indicate if changes were made.

\section{References}

1. Cui P, Zhu X (2011) Surge generation in reservoirs by landslides triggered by the Wenchuan earthquake. J Earthq Tsunami 05(05): 461-474

2. Müller L (1964) The rock slide in the Vajont Valley. Rock Mech Eng Geol 2(3-4):148-212
3. Noda E (1970) Water waves generated by landslides. Proc ASCE 96(2):307-333

4. You Y, Cheng Z (2005) Modeling experiment of debris flow in Midui Gully, Tibet. J Mt Res 23(3):288-293

5. Ataie-Ashtiani B, Najafi-Jilani A (2008) Laboratory investigations on impulsive waves caused by underwater landslide. Coast Eng 55(12):989-1004

6. Fritz HM, Hager WH, Minor HE (2004) Near field characteristics of landslide generated impulse waves. J Waterw Port Coast Ocean Eng 130(6):287-302

7. Heller V, Hager WH (2011) Wave types of landslide generated impulse waves. Ocean Eng 38(4):630-640

8. Wieczorek GF, Geist EL, Motyka RJ, Jakob M (2007) Hazard assessment of the tidal inlet landslide and potential subsequent tsunami, Glacier Bay national park, Alaska. Landslides 4(3): 205-215

9. Zweifel A, Hager WH, Minor HE (2006) Plane impulse waves in reservoirs. J Waterw Port Coast Ocean Eng 132(5):358-368

10. Huber A, Hager WH (1997) Forecasting impulse waves in reservoirs. Proc 19th Congrès des Grands Barrages, Florence, ICOLD, Paris, pp 993-1005

11. Zitti G, Ancey C, Postacchini M, Brocchini M (2016) Impulse waves generated by snow avalanches: momentum and energy transfer to a water body. J Geophys Res Earth Surf 121(12): 2399-2423

12. Mulligan RP, Take WA (2017) On the transfer of momentum from a granular landslide to a water wave. Coast Eng 125:16-22

13. Han L, Wang P (2018) Prediction of the maximum near-field wave amplitude of impulse waves generated by three-dimensional landslides based on momentum balance. Chin J Rock Mech Eng 37(11):165-173

14. Fritz HM, Hager WH, Minor HE (2001) Lituya bay case: rockslide impact and wave run-up. Sci Tsunami Hazards 19(1):3-19

15. Wang B, Yao L, Zhao H, Zhang C (2018) The maximum height and attenuation of impulse waves generated by subaerial landslides. Shock Vib 2018:1-14

16. Yueping Y (2009) Rapid and long run-out features of landslides triggered by the Wenchuan earthquake. J Eng Geol 17(2): $153-166$ 